\title{
The Role of Bilateral Inferior Petrosal Sinus Sampling in the Diagnosis of Cushing's Syndrome
}

\begin{abstract}
Adrenocorticotropin hormone (ACTH)-dependent Cushing's syndrome is most often due to a pituitary corticotroph adenoma, with ectopic ACTH-secreting tumors representing approximately $15 \%$ of cases. Biochemical and radiological techniques have been established to help distinguish between these two entities, and thus aid in the localization of the neoplastic lesion for surgical resection. The test that offers the highest sensitivity and specificity is bilateral inferior petrosal sinus sampling (BIPSS). BIPSS is an interventional radiology procedure in which ACTH levels obtained from venous drainage very near the pituitary gland are compared to peripheral blood levels before and after corticotropin hormone ( $\mathrm{CRH}$ ) stimulation. A gradient between these two locations indicates pituitary Cushing's, whereas the absence of a gradient suggests ectopic Cushing's. Accurate BIPSS results require hypercortisolemia to suppress normal corticotroph ACTH production and hypercortisolemia at the time of the BIPSS to assure excessive ACTH secretion. In some cases, intrapituitary gradients from side-to-side can be helpful to localize small corticotroph adenomas within the sella. BIPSS has rare complications and is considered safe when performed at centers with experience in this specialized technique. (Arq Bras Endocrinol Metab 2007;51/8:1329-1338)
\end{abstract}

Keywords: IPSS; BIPSS; Cushing's; Ectopic; Pituitary; Bilateral inferior petrosal sinus sampling

\section{RESUMO}

\section{O Papel da Amostragem Bilateral do Seio Petroso Inferior no Diagnóstico da Síndrome de Cushing.}

A síndrome de Cushing (SC) ACTH-dependente é mais freqüentemente devida a um adenoma corticotrófico da hipófise, com os tumores ectópicos secretores de ACTH representando aproximadamente $15 \%$ dos casos. Técnicas bioquímicas e radiológicas foram estabelecidas para permitir a distinção entre essas duas entidades e, assim, auxiliar na localização da lesão neoplásica para ressecção cirúrgica. $O$ teste que oferece a mais alta sensibilidade e especificidade é a coleta bilateral de amostras de sangue do seio petroso inferior (BIPSS). BIPSS é um procedimento de intervenção radiológica no qual os níveis de ACTH obtidos da drenagem venosa bem próxima da hipófise são comparados com os níveis sanguíneos periféricos antes e após estímulo com corticorrelina (CRH). Um gradiente entre essas duas localizações indica SC hipofisário, enquanto a ausência de gradiente sugere SC ectópica. Resultados acurados na BIPSS requerem a presença de hipercortisolemia e que ela suprima normalmente a produção de ACTH pelo corticotrofos por ocasião da BIPSS para garantir a secreção excessiva de ACTH. Em alguns casos, os gradientes intra-hipofisários de um lado para outro podem ser úteis na localização de pequenos adenomas corticotróficos no interior da sela. A BIPSS raramente apresenta complicações, sendo considerada segura quando realizada em centros com experiência nessa técnica especializada. (Arq Bras Endocrinol Metab 2007;51/8:1329-1338)

Descritores: IPSS; BIPSS; Síndrome de Cushing; ACTH ectópico; Hipófise; Coleta bilateral do seio petroso inferior

\section{atualização}

\author{
ANDREA UTZ \\ BEVERLY M.K. BILLER
}

Neuroendocrine Unit, Massachusetts General Hospital, Boston, Massachusetts, USA.

Recebido em 15/09/07

Aceito em 22/09/07 
$\mathrm{T}$ 'He evaluation of A Patient with Cushing's syndrome requires a systematic approach. Following the establishment of pathologic hypercortisolemia and adrenocorticotropin hormone (ACTH) dependence, the source of ACTH excess is determined. This is essential because cure depends on surgical removal of the tumor. Neoplastic causes of excess ACTH include, in descending order of prevalence, pituitary corticotroph adenomas, ectopic ACTH-secreting tumors, or very rarely ectopic corticotropin releasing hormone $(\mathrm{CRH})$-secreting tumors. Methods to distinguish between these entities have evolved and will be discussed below. Table 1 lists the biochemical tests that have been most carefully examined for their usefulness in distinguishing between pituitary and ectopic ACTH hypersecretion.

The tests shown in table 1 rely on the assumption that although they are autonomous neoplastic lesions, pituitary corticotroph adenomas retain at least partial responsiveness to suppression by elevated glucocorticoid levels or stimulation by CRH or desmopressin, and conversely that ectopic ACTH-producing tumors do not have such regulation. While this is generally true, variability in the responsiveness of both types of tumors underlies the lack of $100 \%$ accuracy with these tests. For instance, some corticotroph adenomas, particularly macroadenomas, are not suppressed by high-dose glucocorticoids (1), and some are not stimulated by CRH; whereas some ectopic ACTH-secreting tumors show suppression by glucocorticoids and/or stimulation by CRH (2).

Pituitary imaging does have a role in determining the cause of ACTH hypersecretion; however, certain caveats must be considered. Incidental pituitary lesions are relatively common in the general population (3) and thus a small lesion does not assure a pituitary source of ACTH. Conversely, the absence of a lesion on pituitary imaging does not rule-out a pituitary source, as many corticotroph adenomas are very small and undetectable by MRI (4). The size at which a pituitary lesion is nearly certain to be a corticotroph adenoma, rather than an "incidentaloma," is a matter of controversy. While the presence of a pituitary macroadenoma (i.e. lesion $\geq 10$ $\mathrm{mm}$ ) in the setting of ACTH-dependent Cushing's syndrome likely represents pituitary Cushing's, some suggest that lowering the lesion size cut-off to $>6 \mathrm{~mm}$ prevents unnecessary BIPSS procedures without a significant sacrifice in specificity (5).

The characteristics of the tests above have been previously well described in the differential diagnosis of Cushing's syndrome. High dose dexamethasone suppression testing continues to be used frequently to distinguish between ectopic and pituitary Cushing's; however reports of low sensitivity (65-100\%) and specificity $(60-100 \%)$, make this test insufficient as a sole means to indicate surgery $(2,6)$. The peripheral CRH stimulation test has been reported to have a sensitivity that ranges from $70-93 \%$ and a specificity of $95-100 \%$ (7). BIPSS series show the following ranges: sensitivity of $88-100 \%$ and specificity $67-100 \%(2,7,8)$.

The choice of testing protocol used to distinguish pituitary from ectopic Cushing's varies by institution and depends on many factors including accessibility of the specialized BIPSS interventional radiology technique, financial considerations, availability of $\mathrm{CRH}$, and sensitive MRI radiology equipment. Some centers support a step-wise approach by performing the less invasive high dose dexamethasone suppression and peripheral CRH stimulation tests first. It has been reported that concordant positive results for both of these tests predicts pituitary Cushing's with 98\% accuracy. However, 18 to $65 \%$ of pituitary Cushing's patients do not have concordant results and additional testing, usually BIPSS, is the next step for diagnosis (9). Due to the relatively high percentage of patients that will not be accurately diagnosed with these less invasive procedures, some centers proceed directly to BIPSS after the establishment of ACTH-dependent hypercortisolemia.

\section{BIPSS RATIONALE}

ACTH-dependent Cushing's syndrome is defined as the presence of normal or elevated levels of ACTH in the setting of hypercortisolemia. The presence of detectable ACTH in the systemic circulation does not

Table 1. Biochemical testing in the differential diagnosis of ACTH-dependent Cushing's syndrome.

\begin{tabular}{l}
\hline High dose two-day dexamethasone suppression test (HDDST) \\
Eight milligram overnight dexamethasone suppression \\
Metyrapone stimulation \\
Peripheral CRH stimulation \\
Desmopressin stimulation \\
Bilateral inferior petrosal sinus sampling (BIPSS) with CRH stimulation \\
\hline
\end{tabular}


provide any information on the location of the source of the excess ACTH secretion. As the pituitary sella is the most likely location for such a source, it was postulated that the venous drainage from the pituitary, in the presence of a corticotroph adenoma, would likely have a higher ACTH concentration than the systemic circulation.

The first efforts to measure pituitary venous effluent were reported by Corrigan et al. (10) and several other groups contributed significantly to establishing this technique in the differential diagnosis of Cushing's disease $(11,12)$. Initial investigations compared unilateral inferior petrosal ACTH levels to peripheral blood levels. However, it was later established that ACTH levels in venous drainage from the pituitary may be asymmetric, either due to corticotroph adenoma location or anatomical variation. Pituitary venous drainage is usually ipsilateral, so that venous effluent on the contralateral side, relative to the corticotroph adenoma, may not have high ACTH values. In addition, some patients have asymmetric venous anatomy. Thus, simultaneous measurements from both inferior petrosal sinuses are necessary to avoid a falsely negative evaluation in the setting of a pituitary corticotroph adenoma (12). The technique has therefore been termed bilateral inferior petrosal sinus sampling (BIPSS).

The success of BIPSS is dependent on the suppression of the normal corticotrophs in the pituitary gland by the longstanding hypercortisolemia associated with Cushing's syndrome. This prevents basal ACTH release or CRH-stimulated ACTH release by normal pituitary corticotrophs. Suppression of the normal cells ensures that any measurable plasma ACTH in the samples has been secreted by neoplastic tissue. The magnitude and duration of hypercortisolemia required to fully suppress normal corticotrophs is unknown. In normal individuals without hypercortisolemia, ACTH levels may be high due to normal pulsatile corticotroph ACTH release, and normal corticotrophs respond to stimulation by $\mathrm{CRH}$. This leads to absolute ACTH levels and central to peripheral ACTH ratios, obtained via BIPSS, in the same range as seen in true pituitary Cushing's disease (figure 1) (13). Thus, in the absence of sustained hypercortisolemia (to suppress normal corticotroph function), a central to peripheral ACTH gradient, identical to that seen in pituitary Cushing's, may occur. This means that the diagnosis of Cushing's syndrome (i.e. endogenous cortisol excess) must be established before performing BIPSS. In addition, the patient must be hypercortisolemic at the time of the
BIPSS and not controlled with medical therapy or adrenalectomy. Confirmation of hypercortisolemia with a 24-hour urine cortisol or late-night salivary cortisol measurement performed immediately prior to the BIPSS procedure is important.

\section{BIPSS ANATOMY}

Miller and Doppman (14) provide a detailed description of the venous anatomy and technique of bilateral inferior petrosal sinus sampling (figure 2). In the majority of individuals, each inferior petrosal sinus narrows to become a vein (approximately 2 $\mathrm{mm}$ in diameter) that empties directly into the ipsilateral internal jugular vein. In approximately $25 \%$ of people, the drainage of the inferior petrosal sinus is a plexus of channels emptying into the internal jugular vein. In a small percentage of individuals $(0.6-7 \%)$, there is no connection between the inferior petrosal sinus and the internal jugular vein, making standard sampling impossible $(14,15)$. In approximately $60 \%$ of individuals, pituitary venous drainage is symmetric (16), with the majority of the venous effluent from each side of the pituitary draining into the ipsilateral inferior petrosal sinus (14). Thus, the location of a corticotroph tumor within the sella can affect the levels of ACTH in pituitary venous drainage on that side. In some cases, this can assist in lateralization of the tumor and is the rationale for calculating an interpetrosal gradient between left and right sides. More importantly, this explains the necessity to catheterize both inferior petrosal sinuses, as the contralateral side, relative to the tumor, may have ACTH levels similar to the periphery. This could mistakenly lead to misclassification as an ectopic ACTH source if only the contralateral side was sampled.

\section{BIPSS PROCEDURE}

Table 2 outlines the basic procedure for performing BIPSS. The details of catheter choice and radiographic technique are beyond the scope of the current review and interested readers are referred to the interventional radiology literature (14).

The patient is placed in the supine position on the fluoroscopy table. Each groin is prepared in sterile fashion for intravenous access. The femoral vein is cannulated, guide wire inserted, and then needle and wire are exchanged for a venous sheath and this is repeated 

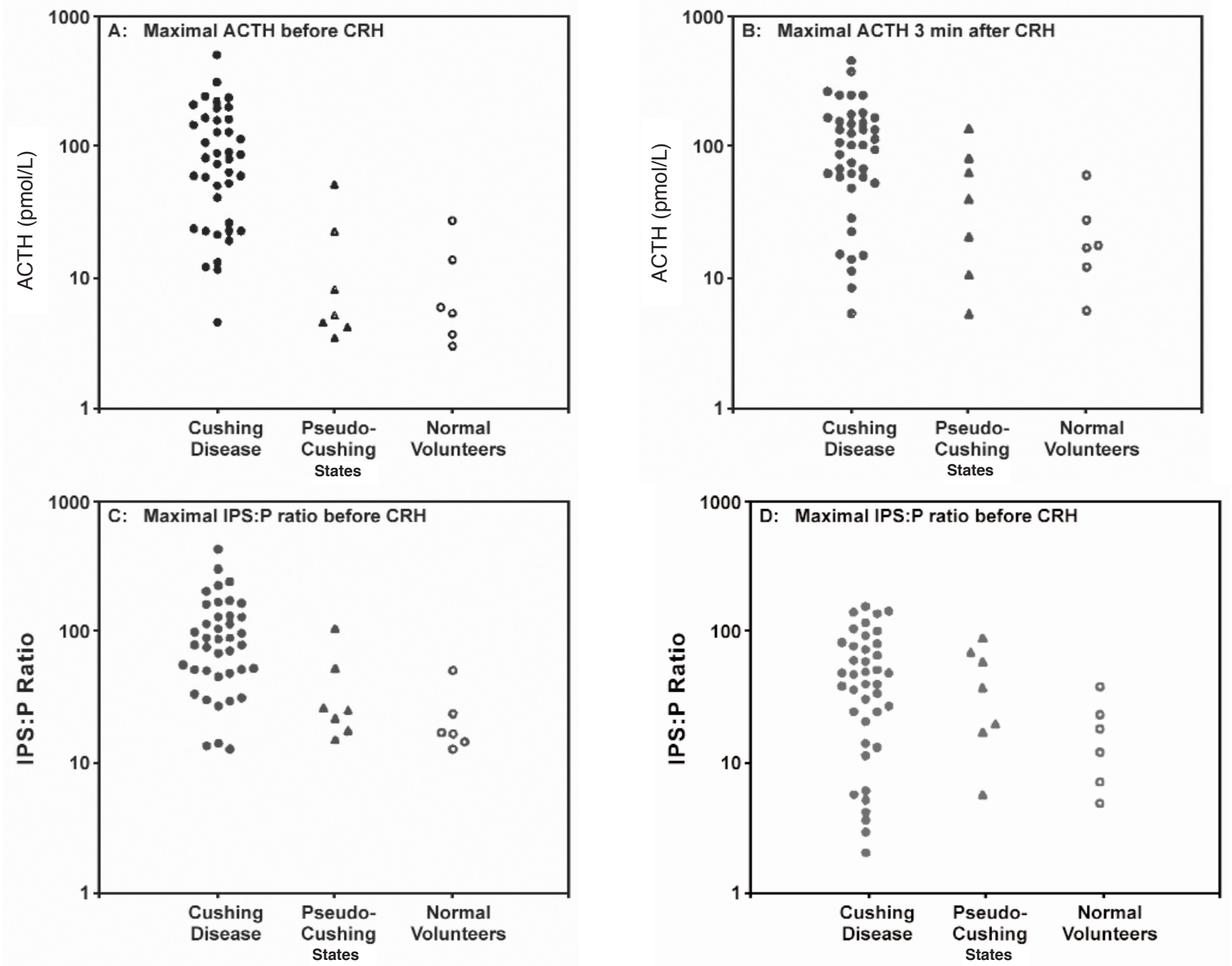

Figure 1. Maximal ACTH concentrations (A) pre-CRH and (B) post-CRH; and central to peripheral ACTH ratios (IPS:P ratio) (C) pre-CRH and (D) post-CRH during BIPSS in patients with Cushing's disease, pseudo-Cushing's, and normal volunteers. ACTH $(\mathrm{pg} / \mathrm{ml})=\mathrm{ACTH}(\mathrm{pmol} / \mathrm{L}) \times 4.55$. [Modified from (13) with permission]

A

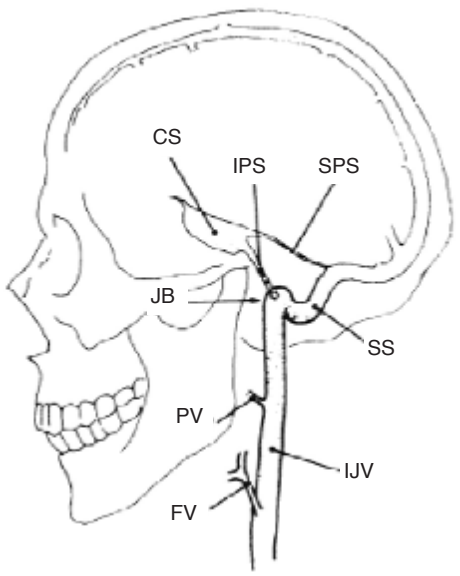

B

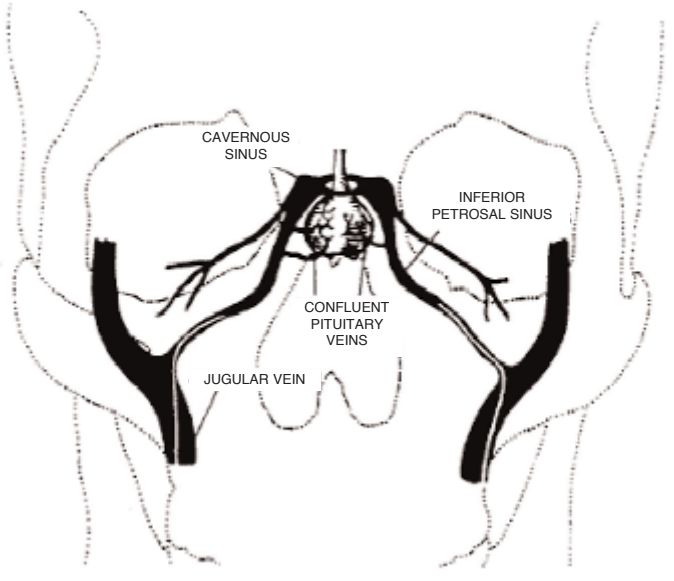

Figure 2. Schematic views of the pituitary venous drainage. (A) Sagittal, (B) Coronal CS: cavernous sinus, IPS: inferior petrosal sinus, SPS: superior petrosal sinus, JB: jugular bulb, SS: sigmoid sinus, IJV: internal jugular vein, FV: facial vein, PV: pharyngeal vein. [Reproduced from $(14,37)$ with permission] 
Table 2. Basic BIPSS procedure.

Conscious sedation
Sterile preparation of bilateral femoral veins at the groin with insertion of venous sheaths
Heparin infusion
Fluroscopically-guided placement of catheters into bilateral inferior petrosal sinuses
Contrast-enhanced fluoroscopy to confirm reflux into ipsilateral cavernous sinus
Obtain baseline blood samples
CRH injection
Obtain post-CRH injection blood samples
Catheter removal and groin pressure until venous hemostasis

on the opposite side. Catheters are then advanced from the groin to each inferior petrosal sinus. Usually heparin is infused before catheters are advanced. Correct catheter placement is confirmed by injection of contrast dye and fluoroscopic imaging assessment. Occasionally, it is not possible to perform BIPSS via a femoral approach (due to inferior vena cava filters, thrombosis, aberrant anatomy, or inability to cross the internal jugular valve) and other access, such direct internal jugular access is used.

After the correct placement of catheters, simultaneous blood samples are obtained from each of the three ports (peripheral, left inferior petrosal sinus, and right inferior petrosal sinus). After obtaining baseline samples (usually 2 sets of baseline samples are obtained), $\mathrm{CRH}$ is injected as a bolus peripherally at $1 \mathrm{mcg} / \mathrm{kg}$ (maximum $100 \mathrm{mcg}$ ) and post-CRH samples are obtained from each port at 3, 5, 10, and 15 minutes. Blood samples are immediately placed into lavender-top EDTA-containing tubes and placed on ice. Processing of the blood, including centrifugation and plasma decantation should occur within one hour and samples are analyzed immediately or frozen until ACTH assay.

Many corticotroph adenomas are susceptible to stimulation by $\mathrm{CRH}$, and this has been exploited to increase the sensitivity of BIPSS. It should be noted that two different forms of CRH, ovine CRH (oCRH) and human CRH (hCRH), have been used in the various reported studies of CRH stimulation. A report by Nieman et al. compared the responses in 15 patients with Cushing's disease following stimulation with ovine and human $\mathrm{CRH}$ and found the peripheral ACTH and cortisol responses to ovine CRH were significantly higher than with human CRH (17).

\section{BIPSS DATA INTERPRETATION}

Simultaneous measurements of ACTH levels in the systemic circulation (peripheral) and in each inferior petrosal sinus (central) are used for calculations. Ratios are calculated at baseline and at each time point after CRH injection, between the left IPS and periphery and between the right IPS and periphery. Of note, the inferior petrosal sinus time point with the highest central to peripheral ACTH ratio is used for interpretation. Based on the largest published series of BIPSS data, established criteria for a central (pituitary) source of excess ACTH are a pre-CRH stimulation central:peripheral ratio $\geq 2.0 \mathrm{OR}$ a post-CRH stimulation ratio $\geq 3.0$ (18). By convention, a "positive" BIPSS represents centralization, i.e. a pituitary source of ACTH excess; whereas a "negative" BIPSS represents an ectopic source of ACTH. Examples of typical BIPSS data in pituitary and ectopic Cushing's are shown in table 3 .

\section{BIPSS TESTING CHARACTERISTICS}

The initial studies of BIPSS suggested near-perfect sensitivity and specificity. As further reports of BIPSS series have been published, diagnostic errors have surfaced. Many of these suggest that errors may be attributed to an inability to access the inferior petrosal sinus, either due to technique or individual anatomy. Reports of diagnostic accuracy may not include data from sampling that has been deemed inadequate or may exclude patients in whom the final diagnosis is unknown. This must be considered when interpreting the resulting data and will lead to lower actual sensitivity of BIPSS in clinical practice. As data continue to accumulate on the accuracy of BIPSS, most studies suggest a high degree of specificity with lesser sensitivity. BIPSS series show the following ranges: sensitivity of $88-100 \%$ and specificity $67-100 \%(2,7,8)$.

As the pre-test probability of a pituitary source of Cushing's syndrome is high at approximately 70\% (7), small decrements in sensitivity will significantly 
Table 3. Examples of BIPSS results data represent ACTH levels in $\mathrm{pg} / \mathrm{ml}$ units.

\begin{tabular}{lccccc}
\hline & Peripheral & Left IPS & Right IPS & $\begin{array}{c}\text { Highest } \\
\text { IPS:peripheral } \\
\text { ratio }\end{array}$ & $\begin{array}{c}\text { Lateralization } \\
\text { ratio }\end{array}$ \\
Pituitary Cushing's & 32 & 110 & 74 & $110 / 32=\mathbf{3 . 4 4}$ & \\
Basal & 34 & 563 & 110 & & $563 / 110=\mathbf{5 . 1 2}$ \\
3 min post-CRH & 39 & 630 & 176 & & \\
5 min post-CRH & 43 & 725 & 210 & $725 / 43=\mathbf{1 8 . 1 3}$ & \\
10 min post-CRH & 54 & 304 & 280 & & \\
15 min post-CRH & & & & & \\
Ectopic Cushing's & 33 & 41 & 38 & $41 / 33=\mathbf{1 . 2 4}$ & \\
Basal & 34 & 51 & 35 & $51 / 34=\mathbf{1 . 5 0}$ & \\
3 min post-CRH & 32 & 46 & 36 & & \\
5 min post-CRH & 30 & 44 & 38 & & \\
10 min post-CRH & 34 & 41 & 35 & & \\
15 min post-CRH & & & & & \\
\hline
\end{tabular}

increase the number of pituitary Cushing's patients that are inappropriately classified as ectopic Cushing's. A report by Swearingen et al. showed in 9 patients with negative BIPSS results, that transsphenoidal surgery revealed an ACTH secreting corticotroph adenoma. Most had suggestive, but not definitive, pituitary MRI findings and no other source on detailed body imaging (8). Thus, following a negative BIPSS and a comprehensive radiologic work-up that does not reveal a source of ectopic ACTH production, consideration should be given to transsphenoidal exploration by a highly experienced pituitary surgeon, particularly in the setting of suggestive pituitary MRI findings.

One report highlighted two sources of false positive BIPSS results. The rare entity of ectopic CRH production may confound BIPSS testing, as the data will suggest a pituitary source due to pituitary corticotroph hyperplasia (8). A peripheral CRH level measurement may be helpful in patients with the appearance of hyperplasia on pituitary MRI or in those with persistent hypercortisolemia following transsphenoidal resection and no evidence of adenoma on pathologic assessment.

A second potential cause of decreased specificity is performance of BIPSS in individuals with an adrenal source of cortisol excess. The presence of adrenal nodularity on abdominal imaging may be due to primary adrenal disease or stimulation by elevated ACTH levels. Although ACTH is usually completely suppressed in adrenal Cushing's, levels in the low normal range may be present in some patients with adrenal Cushing's and this can incorrectly indicate that the hypercortisolemia is ACTH-dependent. Peripheral
CRH testing and high dose dexamethasone suppression tests have been utilized in this situation. In the setting of adrenal Cushing's there is a lack of ACTH or cortisol response to CRH and lack of cortisol suppression by dexamethasone $(2,19)$. BIPSS in the setting of adrenal Cushing's shows low absolute ACTH levels but may reach criteria for pituitary Cushing's due to the low value in the denominator of the ratio calculation, producing a false positive result. For example, a maximum central ACTH value of 10 $\mathrm{pg} / \mathrm{mL}$, with a peripheral value of $1 \mathrm{pg} / \mathrm{mL}$ was noted in a patient with adrenal Cushing's. This yielded a ratio of 10 , thereby misclassifying the patient as having pituitary Cushing's (8).

\section{BIPSS FOR CORTICOTROPH ADENOMA LATERALIZATION}

Since corticotroph adenomas may be small, techniques to pinpoint the lesion within the sella can be helpful for resection guidance. In some cases, MRI findings are unequivocal, such as in the case of macroadenomas. However, in the absence of an obvious lesion on MRI or during surgical exploration, additional information gained from the BIPSS may be useful. Calculation of a side-to-side IPS ratio has been employed to predict the tumor site within the pituitary gland. An interpetrosal gradient between right and left inferior petrosal sinus ACTH levels before and/or after CRH stimulation can suggest the side where the adenoma might reside. Criteria for lateralization have been proposed, with a side-to-side gradient $\geq 1.4$ before or after $\mathrm{CRH}$ stimulation indicating 
a lateral lesion and a gradient $<1.4$ indicating a midline lesion, with approximately $70 \%$ accuracy. The highest side-to-side gradient is chosen for this calculation (18). However, the usefulness of lateralization prediction has been questioned, with accuracies ranging from 50 to $100 \%$ (2). Incorrect lateralization may be due to asymmetric pituitary venous drainage, which may be found in up to $40 \%$ of individuals $(16,20)$. However, if venous drainage has been shown to be symmetric with venous angiography and there is an interpetrosal ACTH gradient without an obvious lesion on MRI or during surgical resection, hemihypophysectomy on the side with higher ACTH may be indicated.

\section{BIPSS CONFOUNDERS}

As described above, an accurate BIPSS requires suppression of normal pituitary corticotroph ACTH production. Table 4 lists situations in which there may be inadequate suppression of ACTH from normal corticotrophs. The inability to sample adequately from the inferior petrosal sinus, either due to technical difficulty or due to aberrant venous drainage (21), can prevent the correct prediction that the ACTH-secreting tumor is in the pituitary gland (table 4).

\section{BIPSS RISKS}

Risks of BIPSS are uncommon; however, there are potential adverse events. The most common complication is groin hematoma, occurring in 3-4\% (14).
As the BIPSS procedure involves infusion of iodinated contrast material, there is a risk of acute renal insufficiency that may be exacerbated by pre-existing renal insufficiency or hypovolemia, so measurement of BUN and creatinine is recommended prior to the procedure. Heparin is frequently infused following the insertion of sampling catheters to prophylax against cavernous sinus thrombosis. Thus, pre-procedure assessment of the coagulation system, platelets, and hematocrit is suggested. Additional concerns include radiation exposure during fluoroscopy, heparin-induced thrombocytopenia, and catheter-related infections. The placement of the catheter may cause discomfort, headache, ear pain, or hearing noises. Explaining to the patient in advance that these may occur can prevent anxiety during the procedure.

Very rare complications have included deep venous thrombosis and pulmonary thromboembolism $(22,23)$, pontocerebellar junction stroke (24), brain stem injury (25), cranial nerve palsy (26), and venous subarachnoid hemorrhage and obstructive hydrocephalus (27). Neurologic complications may be due to variant venous anatomy or specific catheter use and at least one report suggests that adverse sequelae may be minimized or averted if the BIPSS is aborted upon development of new neurologic signs or symptoms (25).

\section{ALTERNATIVE BIPSS STRATEGIES}

While sampling from the inferior petrosal sinus provides the highest sensitivity, it is a technically challenging procedure. At institutions without experience

Table 4. Pitfalls in BIPSS.

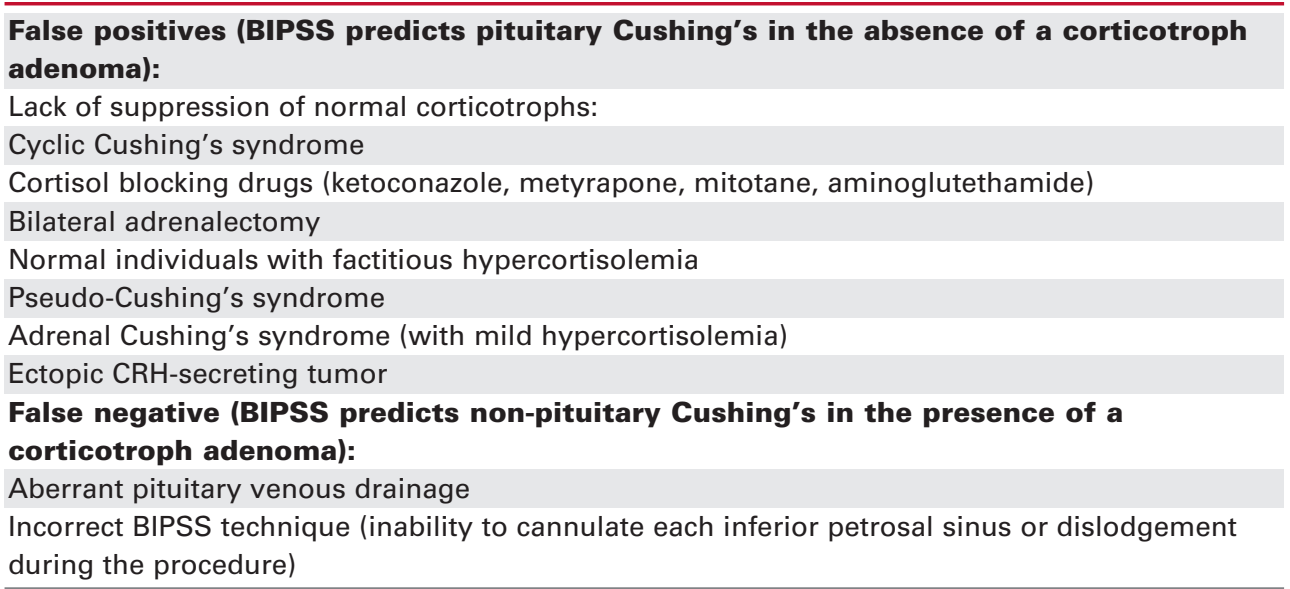


in this procedure, it may be reasonable to proceed with advancing femoral catheters only as far as the internal jugular veins, known as jugular venous sampling (JVS). A study compared the two procedures, performed in the same subjects on separate days, in a population of patients with Cushing's syndrome ( $\mathrm{n}=74$ for pituitary source and $n=11$ with ectopic source). Different central to peripheral ACTH ratio cut-off values were used. For BIPSS, ratios of $>1.6$ pre-CRH and $>2.5$ post-CRH were classified as pituitary Cushing's. For JVS, ratios of $>1.7$ pre-CRH and $>2.0$ post-CRH were classified as pituitary Cushing's. Using these criteria, the test was $100 \%$ specific for both techniques, 94\% sensitive for BIPSS, and 83\% sensitive for JVS (9). A similar study using standard cut-offs of $\geq$ 2.0 pre-CRH and $\geq 3.0$ post-CRH showed sensitivities of $94 \%$ and $81 \%$ for BIPSS and JVS, respectively (28). Thus JVS may be a reasonable first step in centers without expertise in BIPSS. The lower sensitivity of JVS suggests that results indicating an ectopic source may be incorrect; therefore follow-up options include: referral for BIPSS or performance of a detailed radiologic assessment for an ectopic source. In the absence of a demonstrable ectopic source, exploratory pituitary surgery may be indicated if an expert pituitary surgeon is available.

Conversely some centers have reported improved accuracy and intra-sellar localization by sampling more proximally, from bilateral cavernous sinuses $(29,30)$. However, increased risk of cranial nerve palsy with cavernous sinus sampling has been reported (20) and this procedure is not performed at most centers.

The most likely cause of a false-negative BIPSS is the inability to sample bilateral pituitary venous effluent adequately. In the setting of non-centralizing BIPSS results, verification of adequate sampling is valuable. This is generally obtained by reviewing the radiologic films to confirm appropriate catheter placement and standard venous anatomy via angiography. Biochemical confirmation of adequate sampling may be possible by assessing concurrent levels of other anterior pituitary hormones. For example, during BIPSS a central prolactin to peripheral prolactin ratio close to 1.0 may suggest inadequate sampling and if the ACTH results suggest an ectopic location, it may represent a false-negative result with consideration given to transsphenoidal exploration (31). However, previous studies of basal anterior pituitary hormone secretion did not suggest that normalization improved sensitivity of BIPSS testing (32). Further study of this approach would be valuable.
Methods for improving the sensitivity of BIPSS have been explored. Injection of desmopressin (10 mcg intravenous) alone (33) or concurrently with hCRH has been examined for its ability to increase the stimulation of ACTH release by corticotroph adenomas. Following hCRH and desmopressin injection, a post-stimulation central:peripheral ACTH ratio of > 2.0 produced a sensitivity of $97.9 \%$ and specificity of $100 \%$ for Cushing's disease (34). Pre-treatment with metyrapone for 24 to 48 hours prior to BIPSS, to increase pituitary ACTH output, has been explored and may increase sensitivity when $\mathrm{CRH}$ is not available (35).

While it is appropriate to rule-out pseudoCushing's prior to utilizing the BIPSS technique to distinguish between pituitary and ectopic Cushing's, in occasional patients the distinction between trueCushing's and pseudo-Cushing's may be difficult. In these instances, assessment of central CRH levels could theoretically be helpful in distinguishing between the two disorders. Unfortunately, CRH levels in the inferior petrosal sinuses were at or below the limits of detection of the $\mathrm{CRH}$ assay in normal individuals, those with pseudo-Cushing's, and Cushing's disease, even when opiate and benzodiazepine sedation was withheld (36).

\section{CONCLUSION}

At present, there is not a single test, or series of tests, that can definitively locate the tumor source in ACTH-dependent Cushing's syndrome with 100\% accuracy. In the absence of BIPSS availability, pituitary imaging and dynamic testing with agents such as dexamethasone, CRH, desmopressin and metyrapone remain the standard approach to diagnosis. In patients without a suggestive pituitary lesion on MRI of greater than $1 \mathrm{~cm}$ in size, inferior petrosal sinus sampling provides excellent specificity and higher sensitivity than other available biochemical testing strategies. In individuals with a centralizing BIPSS, surgery by an expert pituitary surgeon is indicated. In the absence of a centralizing BIPSS, a thorough radiologic assessment for an ectopic tumor may reveal the ACTH source; however, due to the high pre-test probability of pituitary Cushing's disease, in the absence of an ectopic source, pituitary exploration may be considered. Further study is necessary to refine the best testing strategy for ACTH-dependent Cushing's syndrome, including non-invasive biochemical tests, radiological imaging, and invasive tests such as BIPSS. 


\section{REFERENCES}

1. Katznelson L, Bogan J, Trob J, Schoenfeld D, Hedley-Whyte $\mathrm{E}, \mathrm{Hsu} \mathrm{D}$, et al. Biochemical assessment of Cushing's disease in patients with corticotroph macroadenomas. J Clin Endocrinol Metab 1998;83:1619-23.

2. Newell-Price J, Trainer P, Besser M, Grossman A. The diagnosis and differential diagnosis of Cushing's syndrome and pseudo-Cushing's states. Endocr Rev 1998;19:647-72.

3. Ezzat S, Asa S, Couldwell W, Barr C, Dodge W, Vance M, et al. The prevalence of pituitary adenomas. Cancer 2004;101:613-9.

4. Patronas N, Bulakbasi N, Stratakis CA, Lafferty A, Oldfield E, Doppman J, et al. Spoiled gradient recalled acquisition in the steady state technique is superior to conventional postcontrast spin echo technique for magnetic resonance imaging detection of adrenocorticotropin-secreting pituitary tumors. J Clin Endocrinol Metab 2003;88:1565-9.

5. Arnaldi G, Angeli A, Atkinson AB, Bertagna $X$, Cavagnini $F$, Chrousos G, et al. Diagnosis and complications of Cushing's syndrome: A consensus statement. J Clin Endocrinol Metab 2003;88:5593-602.

6. Aron DC, Raff H, Findling JW. Effectiveness versus efficacy: The limited value in clinical practice of high dose dexamethasone suppression testing in the differential diagnosis of adrenocorticotropin-dependent Cushing's syndrome. J Clin Endocrinol Metab 1997;82:1780-5.

7. Lindsay J, Nieman L. Differential diagnosis and imaging in Cushing's syndrome. Endocrinol Metab Clin North Am 2005;34:403-21.

8. Swearingen B, Katznelson L, Miller K, Grinspoon S, Waltman A, Dorer DJ, et al. Diagnostic errors after inferior petrosal sinus sampling. J Clin Endocrinol Metab 2004;89:3752-63.

9. Ilias I, Chang R, Pacak K, Oldfield EH, Wesley R, Doppman J, et al. Jugular venous sampling: An alternative to petrosal sinus sampling for the diagnostic evaluation of adrenocorticotropic hormone-dependent Cushing's syndrome. J Clin Endocrinol Metab 2004;89:3795-800.

10. Corrigan D, Schaff M, Whaley R, Czerwinski C, Earll J. Selective venous sampling to differentiate ectopic ACTH secretion from pituitary Cushing's syndrome. NEJM 1977;196:861-2.

11. Findling J, Aron D, Tyrrell J, Shinsako J, Fitzgerald P, Norman $D$, et al. Selective venous sampling for ACTH in Cushing's syndrome. Ann Intern Med 1981;94:647-52.

12. Doppman J, Oldfield E, Krudy A, Chrousos G, Schulte H, Schaaf $M$, et al. Petrosal sinus sampling for Cushing syndrome: Anatomical and technical considerations. Work in progress. Radiology 1984;150:99-103.

13. Yanovski J, Cutler G, Jr, Doppman J, Miller D, Chrousos G, Oldfield $E$, et al. The limited ability of inferior petrosal sinus sampling with corticotropin-releasing hormone to distinguish Cushing's disease from pseudo-Cushing states or normal physiology. J Clin Endocrinol Metab 1993;77:503-9.

14. Miller D, Doppman J. Petrosal sinus sampling: Technique and rationale. Radiology 1991;178:37-47.

15. Shiu P, Hanafee W, Wilson G, RW R. Cavernous sinus venography. Am J Radiol 1968;104:57-62.

16. Mamelak A, Dowd C, Tyrrell J, McDonald J, Wilson C. Venous angiography is needed to interpret inferior petrosal sinus and cavernous sinus sampling data for lateralizing adrenocorticotropin-secreting adenomas. J Clin Endocrinol Metab 1996;81:475-81.

17. Nieman L, Cutler G, Jr, Oldfield E, Loriaux D, Chrousos G. The ovine corticotropin-releasing hormone $(\mathrm{CRH})$ stimulation test is superior to the human $\mathrm{CRH}$ stimulation test for the diagnosis of Cushing's disease. J Clin Endocrinol Metab 1989; 69:165-9.

18. Oldfield E, Doppman J, Nieman L, Chrousos G, Miller D, Katz $D$, et al. Petrosal sinus sampling with and without corticotropin-releasing hormone for the differential diagnosis of Cushing's syndrome. NEJM 1991;325:897-905.

19. Freda P, Wardlaw S, Jeffrey N, Post K, Goland R. Differential diagnosis in Cushing syndrome: Use of corticotropin-releasing hormone. Medicine 1995;74:74-82.
20. Lefournier V, Martinie M, Vasdev A, Bessou P, Passagia J-G, Labat-Moleur F, et al. Accuracy of bilateral inferior petrosal or cavernous sinuses sampling in predicting the lateralization of Cushing's disease pituitary microadenoma: Influence of catheter position and anatomy of venous drainage. J Clin Endocrinol Metab 2003;88:196-203.

21. Doppman JL, Chang R, Oldfield EH, Chrousos G, Stratakis CA, Nieman LK. The hypoplastic inferior petrosal sinus: A potential source of false-negative results in petrosal sampling for Cushing's disease. J Clin Endocrinol Metab 1999; 84:533-40.

22. Diez J, Iglesias P. Pulmonary thromboembolism after inferior petrosal sinus sampling in Cushing's syndrome. Clin Endocrinol 1997;46:777.

23. Obuobie K, Davies J, Ogunko A, Scanlon M. Venous thrombo-embolism following inferior petrosal sinus sampling in Cushing's disease. J Endocrinol Invest 2000;23:542-4.

24. Sturrock N, Jeffcoate W. A neurological complication of inferior petrosal sinus sampling during investigation for Cushing's disease: A case report. J Neurol Neurosurg Psychiatry 1997;62:527-8.

25. Miller D, Doppman J, Peterman S, Nieman L, Oldfield E, Chang R. Neurologic complications of petrosal sinus sampling. Radiology 1992;185:143-7.

26. Lefournier V, Gatta B, Martinie M, Vasdev A, Tabarin A, Bessou $P$, et al. One transient neurological complication (sixth nerve palsy) in 166 consecutive inferior petrosal sinus samplings for the etiological diagnosis of Cushing's syndrome. J Clin Endocrinol Metab 1999;84:3401-2.

27. Bonelli FS, Huston III J, Meyer FB, Carpenter PC. Venous subarachnoid hemorrhage after inferior petrosal sinus sampling for adrenocorticotropic hormone. AJNR Am J Neuroradiol 1999;20:306-7.

28. Erickson D, Huston J, Young W, Carpenter P, Wermers R, Bonelli $F$, et al. Internal jugular vein sampling in adrenocorticotropic hormone-dependent Cushing's syndrome: A comparison with inferior petrosal sinus sampling. Clin Endocrinol 2004;60:413-9.

29. Graham KE, Samuels MH, Nesbit GM, Cook DM, O'Neill OR, Barnwell SL, et al. Cavernous sinus sampling is highly accurate in distinguishing Cushing's disease from the ectopic adrenocorticotropin syndrome and in predicting intrapituitary tumor location. J Clin Endocrinol Metab 1999; 84:1602-10.

30. Teramoto A, Yoshida Y, Sanno N, Nemoto. Cavernous sinus sampling in patients with adrenocorticotrophic hormonedependent Cushing's syndrome with emphasis on inter- and intracavernous adrenocorticotrophic hormone gradients. J Neurosurg 1998;89:890-3.

31. Findling JW, Kehoe ME, Raff $\mathrm{H}$. Identification of patients with Cushing's disease with negative pituitary adrenocorticotropin gradients during inferior petrosal sinus sampling: Prolactin as an index of pituitary venous effluent. J Clin Endocrinol Metab 2004;89:6005-9.

32. Zovickian J, Oldfield E, Doppman J, Cutler G, Jr, Loriaux D. Usefulness of inferior petrosal sinus venous endocrine markers in Cushing's disease. J Neurosurg 1988;68:205-10.

33. Machado MC, de Sa SV, Domenice S, Fragoso MCBV, Puglia $P$, Pereira MAA, et al. The role of desmopressin in bilateral and simultaneous inferior petrosal sinus sampling for differential diagnosis of ACTH-dependent Cushing's syndrome. Clin Endocrinol 2007;66:136-42.

34. Tsagarakis S, Vassiliadi D, Kaskarelis IS, Komninos J, Souvatzoglou $\mathrm{E}$, Thalassinos $\mathrm{N}$. The application of the combined corticotropin-releasing hormone plus desmopressin stimulation during petrosal sinus sampling is both sensitive and specific in differentiating patients with Cushing's disease from patients with the occult ectopic adrenocorticotropin syndrome. J Clin Endocrinol Metab 2007:92:2080-6.

35. Cuneo R, Lee W, Harper J, Mitchell K, Ward G, Atkinson R, et al. Metyrapone pre-treated inferior petrosal sinus sampling in the differential diagnosis of ACTH-dependent Cushing's syndrome. Clin Endocrinol 1997;46:607-18. 
Utz \& Biller

36. Yanovski JA, Nieman LK, Doppman JL, Chrousos GP, Wilder RL, Gold PW, et al. Plasma levels of corticotropin-releasing hormone in the inferior petrosal sinuses of healthy volunteers, patients with Cushing's syndrome, and patients with pseudo-Cushing states. J Clin Endocrinol Metab 1998;83:1485-8.

37. Oldfield E, Chrousos G, Schulte H, Schaaf M, McKeever P, Krudy $\mathrm{A}$, et al. Preoperative lateralization of ACTH-secreting pituitary microadenomas by bilateral and simultaneous inferior petrosal venous sinus sampling. NEJM 1985;312:100-3.
Address for correspondence:

Beverly M.K. Biller

Massachusetts General Hospital

Bulfinch 457

55 Fruit Street

Boston, MA 02114 USA

Fax: (617) 726-5072

E-mail: bbiller@partners.org 